\title{
Hemorrhagic infarction following open fenestration of a large intracranial arachnoid cyst in a pediatric patient
}

\author{
Tyler Auschwitz, MD, ${ }^{1}$ Michael DeCuypere, MD, PhD, ${ }^{1}$ Nickalus Khan, MD, ${ }^{1}$ \\ and Stephanie Einhaus, MD ${ }^{1-3}$
}

'Department of Neurosurgery, University of Tennessee Health Science Center; ${ }^{2}$ Semmes-Murphey Neurologic \& Spine Institute; and 'Le Bonheur Children's Hospital, Memphis, Tennessee

Intracranial arachnoid cysts are a rare condition thought to be congenital in nature. Treatment of intracranial arachnoid cysts remains controversial based on their variable presentation. Treatment options include CSF shunting, endoscopic fenestration, or craniotomy and open fenestration for larger cysts. The complications of these procedures can include hydrocephalus, subdural hematomas, hygromas, and-more rarely-intraparenchymal hemorrhage. The authors found very few reports of hemorrhagic infarction as a complication of arachnoid cyst fenestration in the literature. The authors report a case of an 18-year-old female patient who suffered an ipsilateral hemorrhagic infarction after craniotomy for open fenestration of an arachnoid cyst.

http://thejns.org/doi/abs/10.3171/2014.9.PEDS14126

KEY WORDS arachnoid cyst; infarction; craniotomy; reperfusion injury; congenital

$\Lambda$ RACHNOID cysts account for $1 \%$ of intracranial space-occupying lesions. They are thought to arise primarily from congenital splitting of arachnoid membranes during development or secondarily due to trauma or inflammation. ${ }^{2,3,15}$ However, the precise etiology of these cysts remains to be elucidated. Intraparenchymal hemorrhage has been reported as a very rare complication of open fenestration of an arachnoid cyst in the literature. ${ }^{1,12}$ Rapid evacuation of arachnoid cysts and chronic subdural hematomas, however, has been associated with intracerebral hemorrhage. It is thought that this rapid decompression causes an abnormality of cerebral vasculature, autoregulational dysfunction, and subsequent reperfusion injury. While the pathogenesis of this complication remains unknown, there is some evidence that gradual slow decompression of large sylvian fissure arachnoid cysts may decrease the incidence of these complications. $1,6,7,13,16$

We report the case of an 18-year-old female patient who presented with intractable progressive headaches with evidence of increased intracranial pressure (ICP). She was found to have a Galassi III arachnoid cyst (Table 1). The patient underwent craniotomy and open fenestration of the cyst. This case was complicated by postoperative intraparenchymal hemorrhage, which we speculate to be a sequela of reperfusion injury. This case highlights a complex, rarely reported postoperative complication of open fenestration.

\section{Case Report}

History and Presentation

This 18-year-old female patient was referred to a neurologist with chronic refractory headaches. The patient described these headaches as being more on the left side than the right. She stated that the headaches had been ongoing since the 4 th or 5 th grade. MRI of the brain revealed a giant left frontotemporal arachnoid cyst with associated midline shift (Fig. 1). The patient was referred for neurosurgical consultation.

On clinical examination, the patient stated that these 
TABLE 1. Galassi classification system for grading of arachnoid cysts

\begin{tabular}{cl}
\hline Type & Definition \\
\hline I & Small, spindle-shaped, limited to anterior middle cranial fossa, usually w/ free communication of CTC. \\
\hline II & Superior extent along sylvian fissure w/ displacement of the temporal lobe. \\
\hline III & $\begin{array}{c}\text { Large, fills the whole middle cranial fossa, w/ displacement of not only the temporal lobe but also the frontal \& } \\
\text { parietal lobes. Little communication w/ subarachnoid space on CTC. }\end{array}$ \\
\hline
\end{tabular}

$\mathrm{CTC}=\mathrm{CT}$ cisternography.

headaches had been progressively worsening over recent years. She also reported some numbness and tingling periodically in her hands and feet. Bilateral papilledema was noted on fundoscopic examination. The remainder of the physical examination was unremarkable. Standard preoperative metabolic and coagulation studies were performed, and the values were within normal limits for age.

\section{Operation}

The patient was taken to the operating room and placed under general anesthesia. Normotensive blood pressure was maintained throughout the case. The patient was placed in a Mayfield head holding device, and the head was turned $30^{\circ}$ to the right. A frontotemporal incision was made, and a small pterional craniotomy was performed. The dura was opened carefully, leaving the arachnoid cyst membranes intact. The arachnoid was visibly bulging and appeared to be under increased pressure. The arachnoid cyst self-decompressed, and CSF began draining from the dural incision. The lateral/outer membranes were resected, allowing direct visualization of the internal carotid and
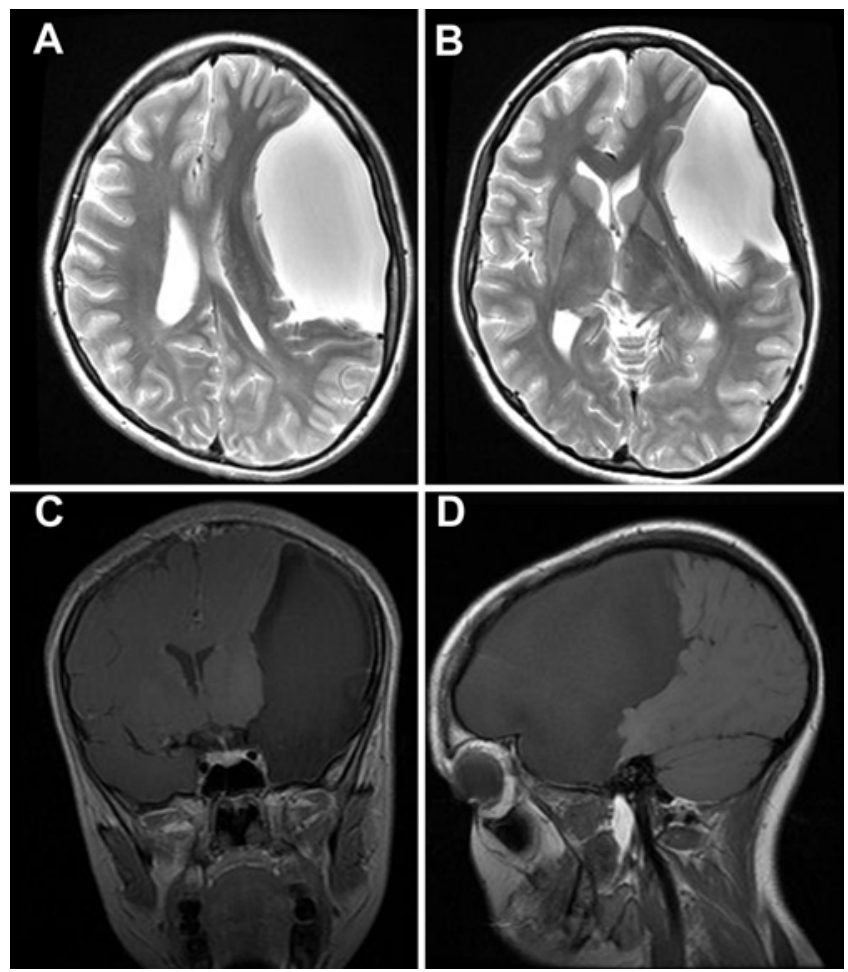

FIG. 1. Preoperative axial T2-weighted (A and B) and coronal (C) and sagittal (D) T1-weighted MRI sequences demonstrating a large left frontotemporal arachnoid cyst. middle cerebral arteries (Fig. 2). The opticocarotid cistern was then fenestrated, and flow was established across this fenestration. Of note, the carotid artery was not manipulated, and there was no direct visual evidence of vascular spasm. The bone flap was replaced with titanium plates, dura and skin were closed in standard fashion, and the patient was extubated in the operating room. She was then taken to the recovery room in stable condition.

\section{Postoperative Course}

The patient was awake and had normal speech and stable vital signs immediately after surgery. She was noted to be moving all of her extremities with full strength. Ninety
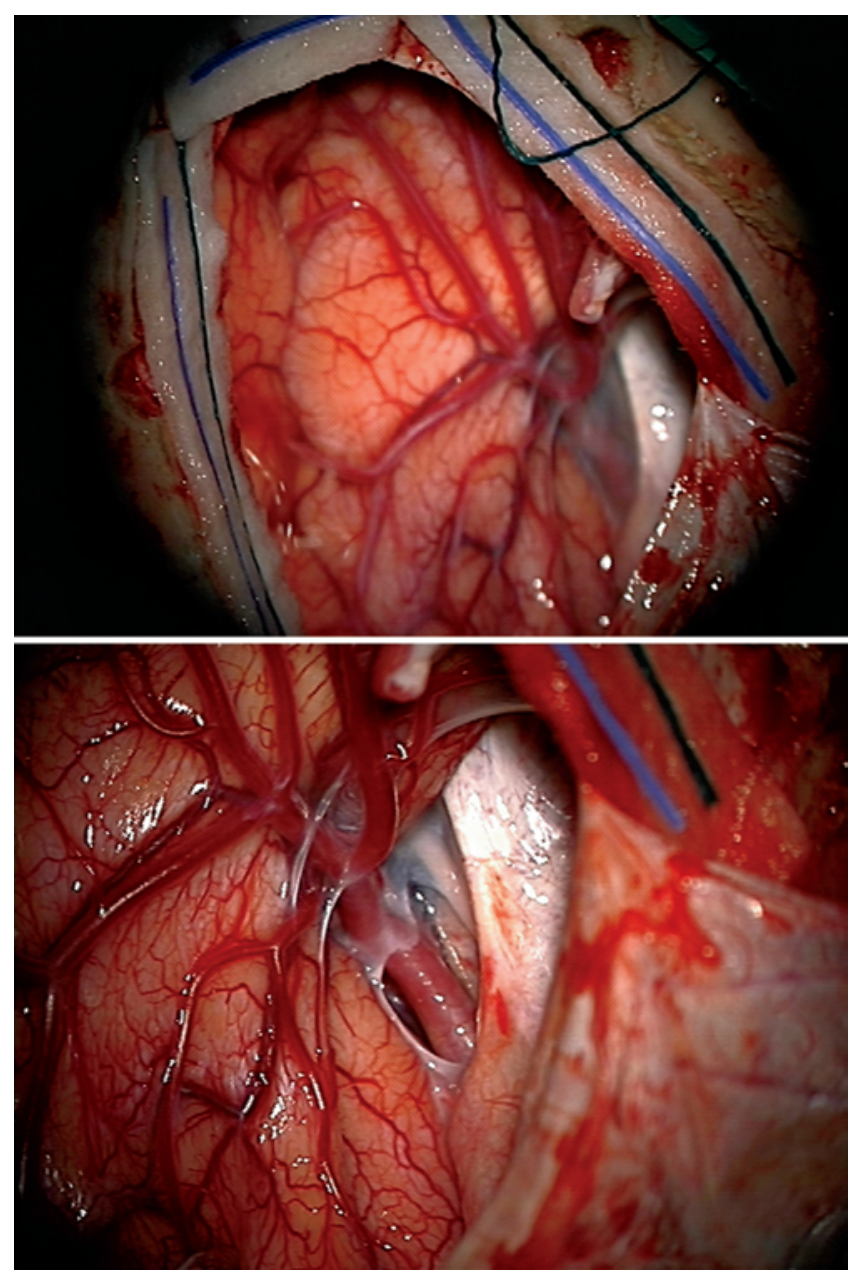

FIG. 2. Intraoperative images of the arachnoid cyst before (upper) and after (lower) fenestration, allowing visualization into the opticocarotid cistern. Figure is available in color online only. 
minutes after the conclusion of the surgical procedure, the patient suffered a partial seizure with secondary generalization in the recovery room. Emergency CT imaging of the head was performed and revealed 3 foci of intraparenchymal hemorrhage in the left middle cerebral artery territory (Fig. 3). It was thought that this most likely represented reperfusion injury. The hematoma was deemed inoperable due to its location within eloquent cortex and lack of mass effect. While in the radiology department, the patient had an apneic episode. She was urgently intubated and transferred to the ICU for further management.

In the ICU an ICP monitor was placed, which showed low-normal ICP. The patient was placed on a regimen of antiepileptic medications and was monitored closely. It was soon noted that the patient was hemiparetic on the right side. The patient remained under close observation in the ICU for an extended period.

The patient received extensive physical, occupational, and speech therapy while she was an inpatient. At discharge from the hospital, she had slight movement of her right upper and lower extremities and had some degree of expressive aphasia. She was transferred to a rehabilitation center for further care.

\section{Follow-Up}

The patient spent approximately 4 weeks at an intense inpatient rehabilitation hospital. The patient made substantial gains in function over this time period. At the 9-month follow-up, the patient was doing well with very few residual deficits (Fig. 4). Of note, the patient had symmetric strength in all 4 extremities and recovered excellent fine motor control in her right hand. She still has some mild word-finding difficulties.
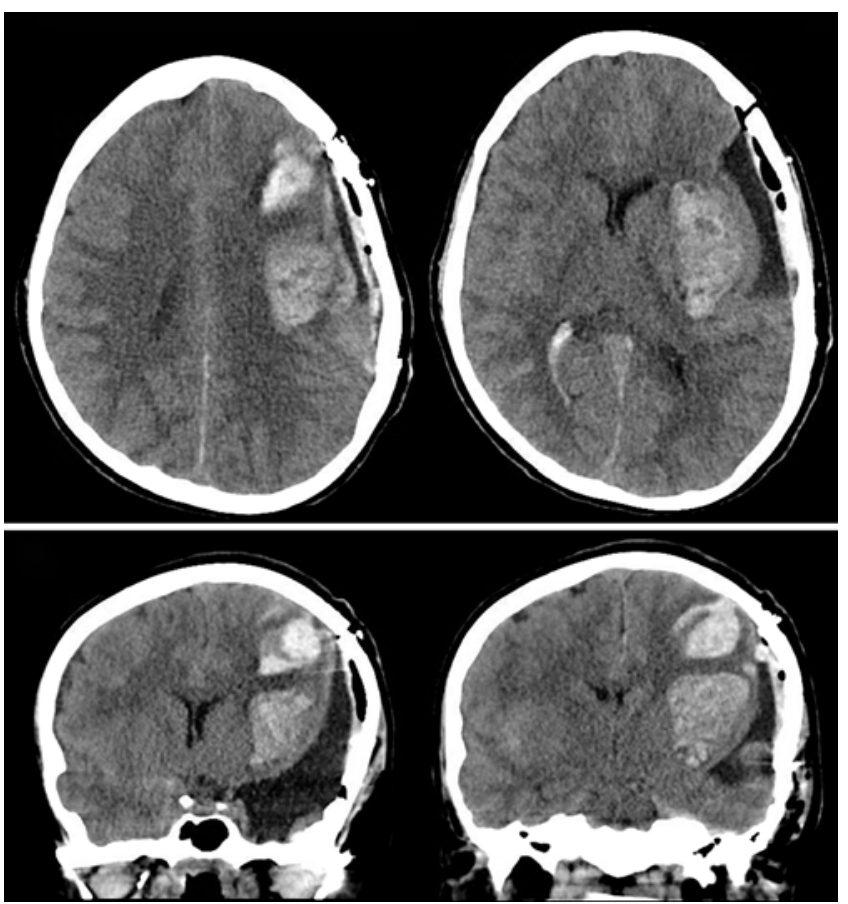

FIG. 3. Postoperative axial (upper) and coronal (lower) CT images of the head showing several foci of intraparenchymal hemorrhage after fenestration of the arachnoid cyst.

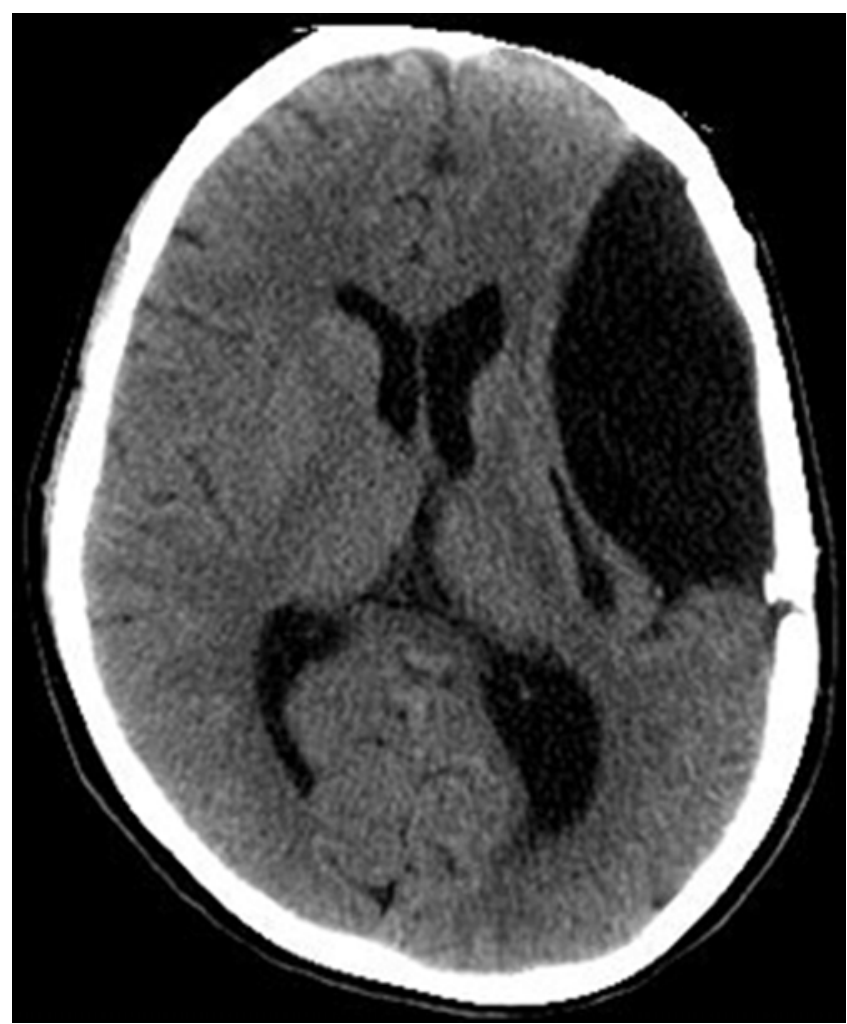

FIG. 4. Axial CT image of the patient's brain obtained 9 months after surgery.

\section{Discussion}

Treatment strategies for large intracranial arachnoid cysts remain controversial. Surgical options include open or endoscopic cyst fenestration, placement of a cystoperitoneal shunt, or marsupialization via craniotomy. Here, we demonstrate a rare complication after craniotomy for open fenestration of a large arachnoid cyst. ${ }^{1,6}$

The majority of arachnoid cysts are found in the supratentorial compartment. Of these, most have been noted to arise in the middle cranial fossa. ${ }^{2,8,17}$ This propensity of arachnoid cyst formation at this site has been attributed to failure of fusion of frontal and temporal arachnoid membranes within the sylvian fissure during fetal development. ${ }^{14}$ Of arachnoid cysts found in the middle fossa, up to $30 \%$ are considered large, occupying nearly the entire temporal fossa. ${ }^{4}$ There have been several theories proposed for possible mechanisms that lead to cyst enlargement. However, a precise understanding of this condition remains unknown.

The symptoms of arachnoid cysts are variable based on their size and anatomical location. The size of arachnoid cysts can be classified using the Galassi system (Table 1). Arachnoid cysts that enlarge may become symptomatic if they compress adjacent neural structures or interfere with CSF circulation. ${ }^{7}$ The most common symptom of a middle cranial fossa arachnoid cyst is headache, ${ }^{2,11}$ followed by proptosis, contralateral motor weakness, and seizures. ${ }^{9,10}$ Suprasellar arachnoid cysts may cause obstructive hydrocephalus, visual impairment, and endocrine dysfunction. Posterior fossa arachnoid cysts often present with cerebel- 
lar symptoms, such as nystagmus and gait abnormalities. ${ }^{7}$ The correlation between the size of the arachnoid cyst and signs and symptoms remains poor.

Subdural hematomas and hygromas have rarely been reported as complications of arachnoid cysts. It is thought that the leptomeningeal vessels and bridging veins are susceptible to rupture due to a congenital weakness in the wall of the arachnoid cyst. Cases of minor trauma associated with an arachnoid cyst and subdural hematomas are widely reported throughout the literature.., 7

Intraparenchymal hemorrhage following evacuation of a large arachnoid cyst may likely represent a reperfusion injury, although no definitive cause has yet been determined for this condition. This hypothesis assumes that these patients experience chronic high cerebral perfusion pressure and poor local autoregulatory response as a direct result of mass effect caused by the arachnoid cyst. Sgouros and Chapman demonstrated that arachnoid cysts may indeed interfere with cerebral blood flow and perfusion. ${ }^{16}$ Impedance of cerebral perfusion may indicate that patients presenting with headaches and papilledema (i.e., signs of increased ICP) are at increased risk for this phenomenon in the postoperative period. In this case, as rapid shift in local cerebral perfusion may lead to reperfusion injury, slow decompression of the arachnoid cyst may be the most appropriate treatment option.

If arachnoid cysts are found incidentally, without signs of increased ICP, rapid decompression may be safe. Based on our experience, patients who demonstrate signs of increased ICP may benefit from slow drainage via either a shunt or externalized drain. These patients may then safely undergo either endoscopic fenestration or craniotomy with cyst fenestration once their cerebral perfusion and autoregulation have normalized.

\section{Acknowledgment}

We thank Andrew J. Gienapp for technical and copy editing, preparation of the manuscript and figures for publishing, and publication assistance with this manuscript.

\section{References}

1. Bahl A, Connolly DJ, Sinha S, Zaki H, McMullan J: Rapid brain shift, remote site hemorrhage, and a spinal hematoma after craniotomy for a large arachnoid cyst. J Pediatr Neurosci 7:106-108, 2012

2. Cincu R, Agrawal A, Eiras J: Intracranial arachnoid cysts: current concepts and treatment alternatives. Clin Neurol Neurosurg 109:837-843, 2007

3. Clemenceau S, Carpentier A: [Intracranial arachnoid cysts. A review.] Rev Neurol (Paris) 155:604-608, 1999 (Fr)

4. Daneyemez M, Gezen F, Akbörü M, Sirin S, Ocal E: Presentation and management of supratentorial and infratentorial arachnoid cysts. Review of 25 cases. J Neurosurg Sci 43:115-123, 1999
5. Donaldson JW, Edwards-Brown M, Luerssen TG: Arachnoid cyst rupture with concurrent subdural hygroma. Pediatr Neurosurg 32:137-139, 2000

6. Esmaeeli B, Eftekhar B: Intraparenchymal hemorrhage after surgical decompression of a Sylvian fissure arachnoid cyst. Neurol India 54:320-321, 2006

7. Gosalakkal JA: Intracranial arachnoid cysts in children: a review of pathogenesis, clinical features, and management. Pediatr Neurol 26:93-98, 2002

8. Hanieh A, Simpson DA, North JB: Arachnoid cysts: a critical review of 41 cases. Childs Nerv Syst 4:92-96, 1988

9. Koch CA, Moore JL, Voth D: Arachnoid cysts: how do postsurgical cyst size and seizure outcome correlate? Neurosurg $\operatorname{Rev} 21: 14-22,1998$

10. Kramer U, Nevo Y, Reider-Groswasser I, Sheuer E, Meyer JJ, Leitner Y, et al: Neuroimaging of children with partial seizures. Seizure 7:115-118, 1998

11. Krupp W, Döhnert J, Kellermann S, Seifert V: Intradiploic arachnoid cyst with extensive deformation of craniofacial osseous structures: case report. Neurosurgery 44:868-870, 1999

12. Mori H, Terabayashi T, Kitazawa T, Sugiyama Y: [Multiple intracerebral hemorrhages immediately after surgical excision of middle fossa arachnoid cysts and evacuation of chronic subdural hygroma. Case report.] Neurol Med Chir (Tokyo) 29:142-145, 1989 (Jpn)

13. Pierangeli E, Gigante N, Pizzoni C: Tapping of a type II Sylvian fissure arachnoid cyst: technical note. Neurol India 51:553-554, 2003

14. Robertson SJ, Wolpert SM, Runge VM: MR imaging of middle cranial fossa arachnoid cysts: temporal lobe agenesis syndrome revisited. AJNR Am J Neuroradiol 10:10071010, 1989

15. Robinson RG: Congenital cysts of the brain: arachnoid malformations. Prog Neurol Surg 4:133-174, 1971

16. Sgouros S, Chapman S: Congenital middle fossa arachnoid cysts may cause global brain ischaemia: a study with 99Tc-hexamethylpropyleneamineoxime single photon emission computerised tomography scans. Pediatr Neurosurg 35:188-194, 2001

17. Zee CS: Extraaxial mass lesions, in: Neuroradiology: A Study Guide. New York: McGraw-Hill, 1996, pp 187-206

\section{Author Contributions}

Conception and design: all authors. Acquisition of data: Auschwitz, DeCuypere, Khan. Analysis and interpretation of data: Auschwitz, DeCuypere, Khan. Drafting the article: Auschwitz, DeCuypere, Khan. Critically revising the article: DeCuypere, Khan. Reviewed submitted version of manuscript: DeCuypere, Khan. Approved the final version of the manuscript on behalf of all authors: Einhaus. Administrative/technical/material support: Einhaus. Study supervision: Einhaus.

\section{Correspondence}

Stephanie Einhaus, Semmes-Murphey Neurologic \& Spine Institute, 6325 Humphreys Blvd., Memphis, TN 38120. email: seinhaus@semmes-murphey.com. 